\begin{abstract}
Iranica
Abstracta Iranica Revue bibliographique pour le domaine irano-aryen

Volume 34-35-36 | 2017

Comptes rendus des publications de 2011-2013
\end{abstract}

\title{
G. Rougemont avec des contributions de Paul Bernard. Inscriptions grecques d'Iran et d'Asie centrale
}

\section{Rémy Boucharlat}

\section{(2) OpenEdition}

1 Journals

\section{Édition électronique}

URL : http://journals.openedition.org/abstractairanica/41798

DOI : 10.4000/abstractairanica.41798

ISSN : 1961-960X

Éditeur :

CNRS (UMR 7528 Mondes iraniens et indiens), Éditions de l'IFRI

Référence électronique

Rémy Boucharlat, «G. Rougemont avec des contributions de Paul Bernard. Inscriptions grecques d'Iran et d'Asie centrale », Abstracta Iranica [En ligne], Volume 34-35-36 | 2017, document 15, mis en ligne le 30 décembre 2016, consulté le 26 septembre 2020. URL : http://journals.openedition.org/ abstractairanica/41798 ; DOI : https://doi.org/10.4000/abstractairanica.41798

Ce document a été généré automatiquement le 26 septembre 2020.

Tous droits réservés 


\title{
G. Rougemont avec des contributions de Paul Bernard. Inscriptions grecques d'Iran et d'Asie centrale
}

\author{
Rémy Boucharlat
}

\section{RÉFÉRENCE}

G. Rougemont avec des contributions de Paul Bernard. Inscriptions grecques d'Iran et d'Asie centrale. London, School of Oriental and African Studies, 2012, 326 p., indices, 75 Pl., 6 cartes et plans (Corpus Inscriptionum Iranicarum, Part II Inscriptions of the Seleucid and Parthian periods and of Eastern Iran and Central Asia. Vol. I Inscriptions in non Iranian Languages)

1 Dans la prestigieuse série du Corpus Inscriptionum Iranicarum, le volume consacré aux inscriptions grecques trouvées en Iran et en Asie centrale, qui inclut l'Afghanistan et le NO du Pakistan, était très attendu. Proposé à l'origine à des épigraphistes français à cause des découvertes de la première moitié $\mathrm{du} \mathrm{XX} \mathrm{X}^{\mathrm{e}} \mathrm{s}$. dans les fouilles de Suse, la tâche échut finalement à $G$. Rougemont qui fut titulaire de l'unique chaire d'épigraphie grecque en France à Lyon. Il bénéficia de l'expérience de l'auteur sollicité auparavant, P. Bernard, l'heureux fouilleur d'Aï Khanoum, site qui livra le plus grand nombre de documents en grec d'Afghanistan (54 numéros). Aï Khanoum, et Suse pour l'Iran (51 documents), fournissent les deux tiers du corpus de plus de 160 numéros.

2 Pour la plupart, les documents du catalogue étaient déjà publiés, les uns célèbres, comme la lettre du roi parthe Artaban II à la cité de Phraata, nom donné alors à Suse (21 ap. J.-C.), une étonnante inscription en grec, très classique, en pleine période parthe au cœur de l'empire, ou l'édit du roi Antiochos III daté de 193 av. J.-C., trouvé en deux exemplaires l'un à Nehāvand en Médie en 1946 et l'autre dans la même région en 1966. 
Citons encore des découvertes un peu plus récentes comme les traductions en grec (et en araméen) des édits d'Aśoka, empereur Maurya au milieu du III ${ }^{\mathrm{e}} \mathrm{s}$. av. J.-C. provenant de Kandahar. Rappelons que le texte grec de la grande inscription trilingue de Šāpūr Ier à Naqš-e Rostam a été publié antérieurement avec les deux autres versions par $\mathrm{Ph}$. Huyse dans le CII Part III, vol. I, en 1999.

3 À l'opposé de ces textes royaux, les ostraca (courtes inscriptions peintes sur des tessons de poteries) de Suse, ou la quinzaine d'« actes d'affranchissement » d'esclave gravés sur des petites tablettes en pierre provenant du même site, ou encore les vases portant des inscriptions à l'encre à Aï Khanoum (versement de monnaies indiennes, ou versement d'huile d'olive), ou graffiti ( noms ou phrases gravés sur un tesson de poterie) constituent des témoignages d'inégale importance, de la vie économique et sociale, mais aussi religieuse, de quelques villes hellénisées, au II ${ }^{\mathrm{s}} \mathrm{s}$. av. J.-C. principalement. Sont également inclus dans le corpus quelques manuscrits sur parchemin, comme les deux actes privés sur parchemin d'Avroman en Médie (Kurdistan) ou des contrats ou quittance également sur parchemin de la région de Bactres ou encore deux textes littéraires sur papyrus d'Aï Khanoum. En revanche, sont exclus les timbres d'amphores qui constituent une spécialité à part.

4 Toutes les inscriptions connues au moment de l'édition sont rassemblées dans ce corpus avec tout l'apparat critique nécessaire, informations sur le document, bibliographie complète, parfois impressionnante, et un commentaire, très fouillé selon l'importance du document, qui bénéficie non seulement de l'amélioration des techniques et des méthodes de l'épigraphie, mais aussi des progrès de la recherche historique depuis un siècle et demi.

5 La répartition des inscriptions dans la partie orientale du monde conquis par Alexandre est très inégale. Suse et Aï Khanoum étaient des villes importantes, mais surtout les deux sites ont été fouillés extensivement. Si on connaît depuis longtemps les inscriptions de Médie et les mots ou graffiti de Persépolis, on voit par quelques témoins que d'autres régions (Parthyène, Drangiane, Arachosie, Gandhara, Bactriane) pourraient un jour livrer d'autres documents inscrits en grec.

6 Il faut savoir gré à l'auteur d'avoir envisagé son corpus des inscriptions grecques des « satrapies supérieures ", puis provinces orientales de l'empire parthe, non seulement pour les spécialistes du monde grec égéen, mais aussi bien pour les historiens de l'Iran et de l'Asie centrale. Si tout ce que veulent trouver les premiers est donné, en particulier dans les notes souvent très copieuses, l'ouvrage est accessible aux seconds grâce à un premier niveau de lecture, la traduction explicite de chaque document et le rappel de données, souvent évidentes pour les épigraphistes du monde grec, mais moins pour les orientalistes. Un tel corpus, maintenant connu sous son acronyme IGIAC, est destiné à être enrichi mais il constitue pour longtemps l'outil dont avaient besoin les historiens des époques séleucide et parthe, mais aussi de l'époque achéménide. 


\section{AUTEURS}

RÉMY BOUCHARLAT

CNRS, Lyon 